\title{
Expresión artística popular en Lima: del afiche chicha a la estética chicha
}

\section{Popular artistic expression in Lima: From the chicha poster to the chicha aesthetic}

Arturo Quispe Lázaro

Universidad Nacional Mayor de San Marcos, Lima, Perú arturo.quispe1@unmsm.edu.pe

Resumen

ORCID: https://orcid.org/0000-0002-1897-5119

El presente artículo examina los puntos iniciales de un proceso creativo que articula nuevas identidades populares en Lima, provienente del circuito económico y cultural de la música chicha. Estas identidades se expresan simbólicamente en la producción gráfica llamada estética chicha, que desde la segunda década del presente siglo se ha posicionado con nuevos bríos en la capital. La estética chicha es una diversidad de producciones gráficas y artístico-culturales que surgió aproximadamente en 2010, y tuvo su origen en el afiche chicha clásico que desde la década de 1970 se publican en las paredes de las casas de barrio en Lima. En el artículo nos centraremos en señalar el proceso que dio origen a las nuevas propuestas gráficas, el tránsito de un proceso creativo anclado a la expresión musical chicha a otro que partiendo de ella descubre un distinto tipo de sensibilidad ligado al arte gráfico, de una generación que se nutrió de la música chicha y que hoy se expresa con voz y sensibilidad propias dando un giro a las producciones culturales del siglo pasado. Todo ello originó una diversidad de creaciones artísticas, se expandió en la ciudad y la denominaron estética chicha.

Palabras clave Estética chicha, música chicha, afiches chicha, sociología del arte, arte y sociedad

\begin{abstract}
This article examines the initial points of a creative process that articulates new popular identities in Lima that comes from the economic and cultural circuit of chicha music. These are symbolically expressed in the graphic production called chicha aesthetics, which since the second decade of this century has been positioned with new vigor in the capital. Chicha aesthetics is a diversity of graphic, artistic and cultural productions that emerged approximately in 2010, it had its origin in the classic chicha poster that has been published on the walls of neighborhood houses in Lima since the 1970s. In the article we will focus on pointing out the process that gave rise to the new graphic proposals, the transition from
\end{abstract}


a creative process anchored to chicha musical expression to another that, starting from it, discovers another type of sensitivity linked to graphic art, of a generation that It was nourished by chicha music and today it expresses itself with its own voice and sensitivity, giving a turn to the cultural productions of the last century. All this originated a diversity of artistic creations, it expanded in the city and they called it chicha aesthetics.

Keywords Chicha aesthetics, Chicha music, Chicha posters, Sociology of art, Society and Art

Fecha de envio: 17/2/2021 Fecha de aceptación: 19/3/2021

\section{Introducción}

Lima, en el cambio de siglo, se siente remecida por dos tipos de movimientos, uno que viene desde el interior, desde la zona amazónica y las regiones del país, y otro del exterior. Desde el interior, una vorágine que se apodera de Lima, la música chicha otra vez impacta la capital, esta vez con la chicha amazónica denominada tecnocumbia (Quispe Lázaro, 2000; Bailón, 2009; Cárdenas, 2014). Y por el ámbito externo viene una creciente globalización que se expresa en una mayor individualidad, a su vez descentramiento social (Martín-Barbero, 1999), donde el centro hegemónico como Lima pierde su protagonismo y las otras zonas del país toman la iniciativa. Ingresamos, como indica Martuccelli (2015), a una socialidad. La tecnocumbia remece la ciudad y genera impacto en todas las áreas y sectores sociales de la ciudad.

Gisèle Freund (2011), en su texto La fotografía como documento social, nos dice que cada momento histórico presencia el nacimiento de unos particulares modos de expresión artística, que corresponden al carácter político, las maneras de pensar y a los gustos de la época (p. 7). El cambio de siglo, con las nuevas circunstancias por la que atravesaba la ciudad y el influjo de la tecnocumbia, se tradujo en nuevas propuestas culturales. La importancia de ese hecho fue lo que generaron, durante y después de aquel movimiento, tanto dentro del circuito de la música misma como en la periferia de ella, jóvenes de distintos espacios sociales, que a raíz de esa vorágine dieron paso a propuestas creativas que vienen del arte y las producciones gráficas ${ }^{1}$. Eso constituía los prolegómenos de lo que más adelante sería la estética chicha.

Desde 2010 la llamada estética chicha adquirió mayor notoriedad en Lima como manifestación cultural popular y durante esos años diversifica su propuesta 
pasando del afiche, a la fotografía, la pintura, el mural, entre otros soportes. Esta producción gráfica tuvo como punto de origen el afiche/cartel chicha. Este artefacto desde la década de 1970 tenía como función y utilidad motivar al público de las zonas populares de Lima a asistir a las fiestas de música chicha o cumbia peruana. En cinco décadas de existencia ha adquirido renombre, reputación y ha generado un impacto dentro y fuera del país.

La estética chicha se enmarca en el denominado "arte popular urbano", el afiche, el grafiti, el mural, etc., en el ámbito de la ciudad. Sin embargo, dentro de un panorama mayor se integraría a propuestas que provienen de otros espacios de lo popular. Uno de ellos es mencionado por Francisco Stastny (1981). En su texto Las artes populares en el Perú Stastny clasifica las principales creaciones de las artes populares en cuatro categorías ${ }^{2}$, y tangencialmente menciona a las nuevas producciones urbanas, no las ubica como un punto más por falta de mayor estudio. "No agregamos aquí una quinta categoría conformada por las creaciones marginales producidas en los niveles populares de las ciudades metropolitanas, tales como los grafitti, decorados de omnibuses y camiones, divisas comerciales artesanales y muchos otros, que constituyen un vasto terreno inexplorado" (p.15). La otra experiencia nos remite a la propuesta de José Ruiz Durand, cuyos afiches fueron catalogados como "pop achorado" en las épocas de la reforma agraria (ver Amigo, 2018; Sánchez, 2016; Flores-Hora, 2006). Sin embargo, la estética chicha se distancia de ellos por la forma de sus diseños y colores brillantes. Producciones que, al expandirse por la ciudad, incursionaron en las galerías de arte como una nueva propuesta del "arte popular" que se produce en la ciudad (Portocarrero, 2015; Quispe Lázaro, 2016b).

En este artículo nos enfocaremos en el proceso inicial de este fenómeno artístico cultural llamado estética chicha. ¿Cómo emerge la estética chicha? ¿Cómo se produce aquel tránsito del afiche chicha a la estética chicha que dio origen a todo ese conjunto de creaciones artísticas? Su importancia radica en visualizar los procesos de creación de una tendencia artístico-cultural y de las dinámicas individuales y sociales que intervienen para su creación. Siendo un producto de reciente creación en el arte, su tratamiento académico recién se inicia. El presente es una suerte de exploración, una investigación analítico-descriptiva, con una metodología inductiva, desde el artefacto artístico, el objeto de estudio, como punto de partida para el análisis respectivo. Abordaremos los siguientes puntos: i) la estética chicha, y sus características; ii) la gráfica chicha: el afiche chicha; iii) el paso de la gráfica chicha a la estética chicha. Conclusiones. 


\section{La estética chicha. Características}

La estética chicha como nombre propio es de reciente creación. Surge a inicios de la década de 2010, creado por asociación de conceptos de distintas personas que trataban de explicar un tipo de producción que provenía del campo de la música chicha vinculado a creaciones artísticas que provenían de otros espacios de lo popular. Antes de esa fecha se las denominaba de distintas maneras: publicidad de la calle, gráfica chicha, etc. Eran los primeros intentos de clasificar estas producciones. Por ello, hay escasas publicaciones físicas (ensayos, artículos académicos, libros) que abordan el tema. Lo que sí existe es una profusión de diversas publicaciones en los medios digitales, Internet y redes sociales de todo tipo, envergadura y densidad, como entrevistas, opiniones, apreciación crítica, publicidad, etc. Están ahí desde artistas plásticos, comunicadores, aficionados al arte, críticos de arte, científicos sociales, entre otros. El medio digital, amplio, variado, de fácil acceso, ha permitido que este tipo de producción se expanda y llegue a todos los sectores sociales de la ciudad de Lima y del país, y, a su vez, que los propios productores expongan sus creaciones artísticas.

La estética chicha es básicamente una producción gráfica diversificada que involucra una serie de artefactos artísticos de distintas materialidades, formatos y motivos. Parte desde el afiche chicha hasta los murales, pasando por la fotografía, la pintura en lienzo y los murales en la ciudad, y se ha expandido a comercios de distinto rubro. Estos trabajos tienen como característica central el color brillante y luminoso, cualidades que por su resplandor también se les dice fosforescentes, y se les reconoce por ser de colores "encendidos". Estas creaciones, al corporizar u objetivizar aquel estilo chicha, se les denomina estética chicha.

¿Cómo surgió la llamada estética chicha? ¿Cuál fue el punto de partida? Según las evidencias, el origen se remonta a los afiches llamados chicha, que fueron (son) utilizados para difundir las fiestas chicha. Veamos estos artefactos publicitarios de origen popular.

\section{La gráfica chicha: afiche chicha}

El afiche chicha (figura 1) es un artefacto cultural que se creó en la década de 1970 y se consolidó con el tiempo. Hay una lógica de producción que involucra dos momentos de manera simultánea: 1) el proceso de producción del artefacto; y 2) la dinámica social y cultural dentro de la cual se desarrolla el proceso creativo, su contexto y recepción. Ambos están íntimamente vinculados, de tal manera 
que todos los elementos que participan de ese medio tienen puntos comunes, un sustrato social y cultural, que sirven de insumo y dan vida a dicho artefacto. Para visualizar esta aproximación veamos los elementos que participan en la producción del afiche, cartel chicha: i) el sujeto creador, quien produce el afiche, y los clientes productores de espectáculos y los grupos de música como fuentes de información; ii) la idea a transmitir, lo que incluye la concepción, el bagaje cultural de los productores y del medio en el que se desenvuelven; iii) cómo se transmite, lo que indica la forma, el diseño y el color que se usarán para dar cuerpo y forma a la idea; iv) con qué o a través de qué se va a transmitir, es decir, la materialidad que dará soporte físico a la idea y también los medios de transmisión; y v) el receptor. Este es diverso según su inserción en la ciudad, su bagaje cultural, sus expectativas de vida, etc.

En esa medida, los componentes que dan vida al afiche chicha forman parte de una dinámica social y cultural que estimula la imaginación, la creatividad, las concepciones culturales de los productores y les provee de las herramientas para su elaboración, desde los medios que se agenciaron y el capital cultural que les sirve de base para la creación del afiche chicha, así como la difusión respectiva. Este último punto también condiciona la materialidad del producto, en tanto que se producirán según los lugares de difusión.

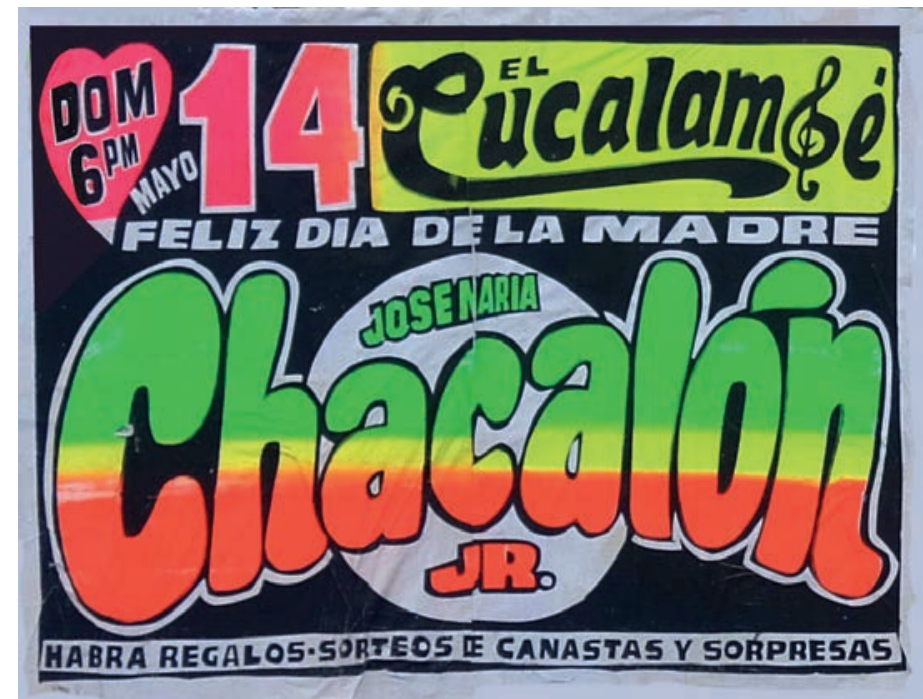

Figura 1. Afiche chicha de Arturo Quispe Lázaro (AQL). 15 de mayo de 2017. 
En tal sentido, el afiche chicha es un artefacto que se fue construyendo con la práctica constante en el medio musical limeño, teniendo como base aquel sustrato social y cultural citado, del cual todos formaron parte. En tiempos aurorales de la música tropical chicha todo estaba en construcción, nadie estaba especializado en nada, ni los músicos, todos eran aficionados, incluso los que producían afiches. Lo que había era una percepción intuitiva de base, mucho ímpetu, gran dedicación y una sensibilidad para aprovechar todo cuanto el medio les proveía a fin de armar un circuito económico-cultural y también de difusión. Dentro de este último el afiche fue el medio adecuado para difundir las fiestas semanales. El afiche fue construyéndose en el camino. Con el tiempo, se fue configurando el estilo, formato, diseño y color que hoy se conocen.

A esta forma de elaboración de afiche chicha, libre, espontánea, Wucius Wong llama informal, porque no fue el resultado de un cálculo previo. Wong diferencia entre una composición formal e informal. La formal se realiza a partir de conceptos matemáticos de traslación, rotación, etc.; y "la composición informal depende de un ojo sensible a la creación de un equilibrio asimétrico y una unidad general mediante elementos y formas libremente dispuestos"(Wong, 2006, p. 14), con balances gráficos y equilibrio en la ubicación de los elementos. El afiche chicha, de esa manera, fue asumiendo un determinado diseño que se fue consolidando con los años hasta constituir una composición, una estructura prácticamente definida, un diseño cuasi único, con pocas variantes, en el que cada dato o información tiene su lugar determinado. El afiche chicha se caracteriza por su diseño, composición, formatos, tipos de letra, y sobre todo por los colores fosforescentes, brillantes. A todo esto se le ha llamado estilo chicha, colores chicha, y sirvieron de base a otras producciones que se diseminaron en la ciudad y originaron la denominada estética chicha. Por lo cual, la nominada estética chicha no se puede entender sin los afiches chicha, que son su punto de partida.

\section{El paso de la gráfica chicha a la estética chicha}

Existen, al menos, dos tipos de conexiones entre la gráfica chicha y la estética chicha. El primero de ellos viene por el lado de las características de los afiches chicha tradicional (aquel que se encuentra en las paredes de los barrios de la ciudad): su diseño, tipo de letras, los colores brillantes, de gran luminosidad, fosforescentes, que se identifica a "lo chicha". El segundo es por la presencia actual de los productores de afiche chicha que participaron en la década de 1980 dentro 
del circuito de la música chicha. Ellos son los llamados "aficheros chicha” y desarrollaron esa labor en los años mencionados. Ellos son, entre otros, Pedro Rojas Meza (cuyo seudónimo es Monky), Feliciano Mallqui y Elliot Urcuhuaranga. Hoy participan activamente dando talleres de producción de afiches chicha con una modalidad distinta. Han participado, junto con otros productores y artistas gráficos y plásticos, en exposiciones en galerías de arte de Lima. De productores de afiches chicha pasaron a dar talleres y fueron los que con su trabajo dieron vida a la hoy "estética chicha".

¿Cómo es que la gráfica chicha pasó a ser un producto de arte? ¿Cómo deviene en una expresión artística que llegó a otros espacios de la sociedad, a las galerías de arte? Brevemente esbozaré aquel tránsito. Lo haré desde tres entradas: i) de la tradición de la música chicha; ii) de lo popular en el arte; y iii) del paso de la gráfica chicha a la estética chicha. Las tres entradas se complementan en el tiempo, pero será en el punto tres que eclosiona e invade la ciudad en el presente siglo. El factor que contribuyó su expansión fue el medio electrónico, Internet y las redes sociales. Si desde la década de 1970 la música chicha musicalizó los barrios de la ciudad e invadió la capital, en el siglo XXI serán sus formas y colores los que impongan su estilo. Lo popular urbano andino adquirió un gran protagonismo en la capital y dio paso a la denominada estética chicha.

\subsection{Desde la tradición de la música chicha}

La denominación estética chicha tiene su origen en la música tropical peruana llamada chicha. Esta es una producción musical creada en Lima a fines de la década de 1960 por peruanos de distintas provincias del país. Su característica central es ser una música producto de la fusión de diversas culturas y expresiones musicales nacionales y extranjeras, que concurrieron para su creación (Núñez y Lloréns, 1981; Degregori, 1984; Romero, 1989; Hurtado, 1985; Quispe Lázaro, 2000, 2004, 2013, 2016a, 2019). Y el punto de mayor jolgorio son las fiestas chicha. Todas las actividades estaban/están orientadas a que se desarrollen dichas fiestas, lo que generó un circuito, un movimiento. Con el tiempo se consolidó un circuito económico que brindó el soporte y dio continuidad a la música chicha; se formaron grupos musicales y estilos a su interior, así como distintas formas de comunicar sus fiestas. Aquel circuito se convirtió en un proceso de producción económica que comprende la producción, la circulación y el consumo de la música. Se desarrolló inicialmente en el medio urbano limeño y luego se extendió al 
resto del país. El circuito fue construido con la concurrencia de creadores, productores y consumidores, y generó un espacio de producción y reproducción de esta forma de expresión musical. El circuito empezaba con la organización de la fiesta y concluía con su realización. En sus inicios las fiestas se organizaron los fines de semana. Concluida la fiesta, terminaba el circuito, y a la semana siguiente iniciaba uno nuevo. Así ha ocurrido con algunos cambios hasta hoy; las fiestas se realizan también durante la semana.

Veamos brevemente cada una de las partes de ese proceso de producción para conocer de dónde procede la ahora denominada estética chicha. El circuito económico se inicia con la producción, que consiste en la creación de la música en sí misma: desde la creación de la música, la composición de sus letras, la participación de los grupos musicales, hasta la elaboración de discos en sus inicios y luego casetes, CD, DVD, videos, etc.

El siguiente proceso económico, la circulación, se refiere a los medios que hacen llegar el producto a los consumidores, es la que vincula la producción y el consumo, son los que difunden el producto. Para ello utilizan diversos medios: los audiovisuales y los gráficos. Se incursionó en el medio audiovisual cuando el circuito ya tenía cierta solidez, que fue en el decenio de 1980, concretamente en programas televisivos. Las emisoras de radio tuvieron un desarrollo distinto. Estas fueron las difusoras por excelencia de este tipo de música, y estuvieron desde el inicio de este género musical. Con el tiempo y su expansión, las emisoras se diversificaron e incluyeron emisoras comunitarias (mercaditos de barrios, con uso de bocinas y altoparlantes), hasta las de radio, que a su vez se dividían según su alcance y ubicación. Están ahí las emisoras locales, distritales, regionales y nacionales.

En el ámbito gráfico se crearon distintas formas de comunicación para dar a conocer las fiestas de música chicha. En la década 1970 se usaron y empezaron a circular los afiches. Desde ese tiempo, su ciclo de vida estaba en función al circuito económico y la realización de las fiestas, entre una o dos semanas, hasta el siguiente ciclo.

La música chicha y todo el circuito, incluido el gráfico, se creó y consolidó porque había la urgencia de cubrir las necesidades básicas de vida de sus cultores. De ese modo, la música, el medio y el circuito se convirtieron en el sustento económico de todos los participantes, desde los músicos y los productores de espectáculos hasta el "recogebotellas" de las fiestas y también los que producían afiches. Era, y es, un medio de trabajo. Es decir, toda la actividad del circuito 
musical estaba centrada y dependía del factor económico. Su organización y producción partía de una racionalidad económica. La intencionalidad del cultor estaba guiada por la misma lógica, como también la producción de afiches. Estos, con el tiempo, se fueron perfeccionando, capitalizando, y sus autores se convirtieron en publicistas gráficos no solo para el medio musical de la chicha, sino también de otros géneros musicales (el huayno, por ejemplo) y otras actividades (Haciendo Perú, 2011; Cuyubamba, 2013).

Desde la década de 1980, la música chicha tuvo un gran impacto en toda la sociedad. Fueron los afiches con sus colores fosforescentes los que impactaron en ciertos espacios de Lima. Algunos de los que se dedicaban a la producción de afiches chicha establecieron redes con otros espacios de la capital. Este fue el inicio de lo que sería otra de las incursiones de la chicha en la ciudad, para las que se dieron varios procesos: uno, que la chicha tuvo un gran impacto en la ciudad; dos, algunos sectores empezaron a considerarla, de manera marginal, un producto que hablaba del nuevo tiempo del país; tres, se empezó a considerar, también de manera marginal, que "lo" chicha, como sus colores, eran una suerte de identidad de la ciudad que provenía de lo popular. Esto sirvió, a su vez, para que estos puentes fueran cimentándose y algunos productores de la gráfica chicha abrieran otro espacio distinto al ambiente musical. De esa manera, cierto sector que participaba del circuito de producción de la música chicha, el de la circulación del producto, se fue independizando, adquiriendo vida propia, de tal forma que asumieron una actividad propia y paralela, sin dejar las características que identificaban a lo chicha. De esa manera, empezaron a crear afiches con la misma característica chicha, pero orientada a otros espacios de Lima distintos al musical. Uno de ellos fue Elliot Urcuhuaranga, conocido como Elliot Túpac, reconocido como el iniciador de esta nueva vertiente de lo chicha en la gráfica, hoy extendida a la ciudad y a las galerías de arte.

\subsection{Desde lo popular en el arte}

En el campo de la plástica, el debate se produjo de manera paralela. En los años 50 se originó un doble influjo de recreación. A nivel social, las migraciones internas llegaron a distintas partes del país y también a Lima. Y desde la plástica, llegaron desde el ámbito externo otros peruanos que traían tras de sí una nueva forma de acercarse a la creación pictórica. Eran los denominados no figurativos, que ya tenían algunos años en el ambiente, pero desde mediados de siglo tuvieron mayor fuerza junto con aquellos que venían de Europa. Se produjo un reacomodo 
económico y también artístico, y empezó a cambiar el norte indigenista de esos años. Se originó un enfrentamiento ideológico artístico en torno a lo abstracto. Era una lucha por imponer un arte y un pensamiento que se concentró en la enconada "polémica del arte abstracto" (Lauer, 2007, pp. 167-168). La polémica en el fondo era el universalismo (abstracto, lo no figurativo) versus el localismo (indigenismo, figurativo); el arte por el arte versus el arte social. Luis Miró Quesada, defensor de los no figurativos, abogaba por "el arte por el arte" y "la necesidad de limpiarlo de toda ideología” (Lauer, 2007, p. 170).

En 1961, Juan Acha indicaba: "La pintura ya ha perdido todo soporte popular" (citado por Lauer, 2007, p. 175). En medio de aquella discusión entre figurativos y no figurativos estaban los abstraccionistas. Lauer pone el acento: "es aquí donde se manifiesta el nuevo punto de ruptura de la plástica peruana, el punto de solución dialéctica del antagonismo entre localismo y universalismo, entre 'arte puro' y 'arte social', entre lo urbano y lo rural” (p. 176). Dicotomías confrontadas, que construyen y deconstruyen. Era la década de 1960, dos lustros después que los migrantes peruanos empezaron a copar Lima, tres años después de la Revolución cubana que incentivó nuevas creaciones y perspectivas nacionalistas y latinoamericanas; algunos años antes del 3 de octubre del 68 de Velasco Alvarado, que le dio un nuevo impulso al arte. Era un punto de discusión importante en el Perú. La clase dominante en el país se reacomodaba y los no figurativos jugaron su rol en ese cometido. A su vez, lo popular emergía a lo largo y ancho del país. Esta era una tensión a ratos en sordina, a ratos expresiva. Lauer se refiere a ese ambiente:

El segundo momento de universalismo de nuestra pintura (representado por la aparición de corrientes figurativas no localistas y de corrientes no figurativas, cuyo polo de objetivación teórica es el abstraccionismo puro), encuentra sus límites en la aparición de un nuevo ciclo de necesidades de reinterpretación nacional, y nueva integración de sectores sociales dominados, por parte de la clase dominante. Por esto la madurez, y por tanto el punto de transformación del universalismo en el Perú de fines de los años 1950 y comienzos de los años 60 están determinados por dos problemas centrales: una vez más el del universo cultural de los dominados, y la posibilidad del símbolo como efectivo signo cultural (Lauer, 2007, p. 179).

Ese nuevo "universo" del que habla Lauer se fue construyendo desde los márgenes de lo social, cultural y artístico, con otro tránsito de lo rural a lo urbano, porque 
fueron los peruanos de distintas partes del país, en las ciudades, y en Lima en particular, los que empezaron a crear desde sus propias motivaciones y bagajes culturales, lo que dio otro matiz al lugar de su nueva residencia. Mientras tanto, las otras expresiones artísticas de aquel tiempo reaccionaban a la nueva realidad de Lima que empezaba a configurarse desde la década de 1950. Las artes plásticas estaban enfrascados en una discusión interna, vital, de supervivencia, justamente por el influjo de nuevas realidades. Manuel Munive dirá al respecto:

En la segunda mitad del siglo pasado, cuando se inicia la transformación de la ciudad por obra de las migraciones internas, la pintura tarda un poco en configurar una imagen de este proceso. Sería más bien la literatura de fines de la década de 1950 la que adelantó a las artes plásticas en el propósito de representar o hacer ingresar con éxito "lo urbano limeño" como línea temática. Surgió así la "narrativa urbana", cuyos pioneros más notables fueron los escritores E. Congrains (Lima, hora cero, 1954) y J. R. Ribeyro (Al pie del acantilado, 1959).

La afirmación anterior no implica que la ciudad haya permanecido invisible en lo plástico durante el intersticio mencionado. Todo lo contrario: se popularizó desde entonces un género pictórico colonial pintoresquista, en que Lima es únicamente la del centro histórico y sus balcones cerrados. La serie $A$ la gloria del balcón limeño, del pintor Wenceslao Hinostroza, expuesta en 1961, así lo ejemplifica. Posteriormente este género, que en todo caso ostentaba una apreciable calidad técnica, decae en una seudopintura que presenta una ciudad animada por “Tapadas” y calesas, hecha para satisfacer únicamente las pretensiones del comercio turístico y que por lo mismo no supera los límites de la mala artesanía (Munive, 2003, p. 8).

Las nuevas realidades de Lima no tenían representación en la plástica. Demoró su presencia debido, según Lauer, a que en los años 50 la clase dominante se solazaba en lo económico sin ningún proyecto de país, porque no lo necesitaba, y menos reinterpretarlo. Su centro fue el interés económico. El tipo de arte que le interesaba estaba centrado en la introspección del individuo como inspiración creativa, en la inmanencia del cuadro.

Mientras tanto, Lima se desbordaba por sus laderas y lo popular andino empezaba a tener protagonismo. Cinco décadas después, no solo tenía presencia en todas las instancias de la sociedad, sino que, además, lo popular urbano de 
raigambre andina mostró su capacidad propositiva en el campo artístico, y devino no como producto de una intencionalidad, de una racionalidad premeditada que busca imponerse en la ciudad para ganar consenso o hegemonía, sino como resultado de las iniciativas individuales desarrolladas por años en el campo popular.

La estética chicha, entonces, es el producto de todo aquello que se inició en los años 1950 en adelante en la ciudad de Lima y en el país, los cambios en el contexto social y cultural, y del influjo de los peruanos de todas las regiones secularmente postergadas. Ellos, con su hacer y actuar, han logrado dar un giro diferente a la creación, con formas distintas de concebir el sonido, la gráfica, no solo en la capital, sino también a nivel nacional.

\subsection{De la gráfica chicha a la estética chicha}

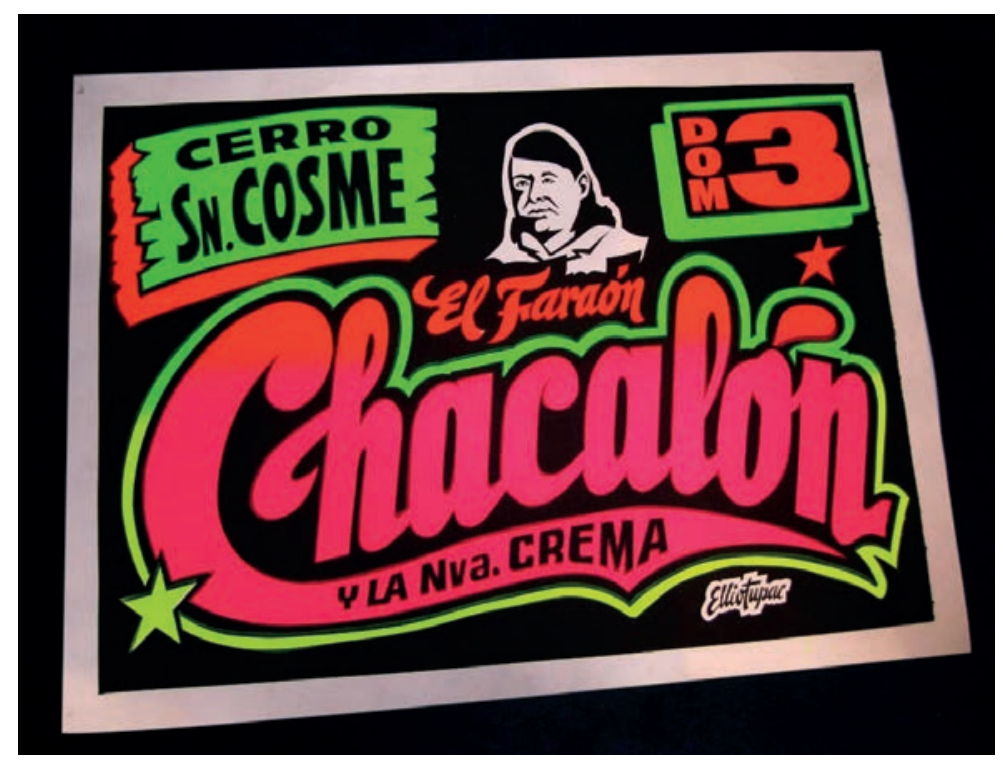

Figura 2. Afiche chicha. Chacalón de Elliot Túpac. En https://www.flickr.com/ photos/elliotupac/5225755534/

Hasta aquí había un artefacto cultural que provenía de lo popular y desde lo chicha que se expresaba en el afiche chicha. Desde inicios de este siglo el mismo sector genera cambios al interior de dicho artefacto, y estimula nuevas formas creativas a lo que se llamó estética chicha. ¿Cómo llegó a denominarse estética chicha? Las figuras 1 y 2 son llamadas afiches chicha. Sin embargo, ambas son 
distintas. La primera es el clásico afiche que desde 1970-1980, con sus cambios en el tiempo, se ha encontrado en las paredes de algunos distritos de la ciudad, aquellos denominados populares; la segunda es otro que se ha creado desde este siglo. El cambio de imagen de un afiche a otro — que en la primera década fue madurando, y en la segunda empieza a tomar cuerpo- ha significado no solo un cambio en el formato y composición, sino también en la lógica de producción y las nuevas expectativas de una nueva generación de jóvenes que proviene de la música chicha y que ha empezado a expresarse en la ciudad. Para evitar confusiones, los he diferenciado y nombrado de manera distinta. A los afiches que se utilizan para publicitar fiestas de música chicha y son expuestos o colocados en la vía pública o lugares visibles de la ciudad los llamo afiches chicha públicos. A los afiches chicha que transmiten ideas o pensamientos, no publicitan fiestas de música chicha, y son expuestos en lugares cerrados o privados los he llamado afiches chicha de galería. Estos no necesariamente se exponen en una galería de arte, y tampoco establecen jerarquía o valoración entre ellos.

Lo importante es visualizar el paso de un formato a otro. Las intencionalidades de creación de ambos son distintos. El primero es destinado a publicitar fiestas, mientras que el segundo transmite ideas, es de mayor elaboración y se le atribuye ser parte de la llamada estética chicha. Ese paso no es un simple cambio de formato, sino la expresión de una nueva manera de identificarse en la ciudad y concebir la creación artística desde lo chicha.

Desde la segunda década, 2010, se produjeron tres situaciones que van en la dirección indicada: i) la producción gráfica antes dirigida a las fiestas chicha (figura 1) cambió de destinatario y se dirigió a un público más amplio, al barrio, y a otros sectores de la sociedad; al mismo tiempo se alteró su contenido, la referencia pasó de ser las fiestas chicha, a una de mayor cobertura, al ámbito popular urbano, a transmitir ideas; sin embargo, mantuvo la estructura inicial de la gráfica y los colores fosforescentes (figura 2); ii) la receptividad de la sociedad, sectores medios y altos, se hizo más permisiva con lo chicha. Ante la inevitable presencia de esta producción gráfica, los distintos sectores de la sociedad la adoptaron a sus fines e intereses, no sin resistencia y confrontación; iii) la producción se masifica. Esta forma de producir los gráficos se diversifica en distintos formatos, materialidad, y soportes, y se extiende en toda la ciudad. Paralelamente, en Internet y redes sociales, se multiplican artículos, ensayos y entrevistas sobre el tema. Al mismo tiempo, se incrementan los grupos de personas, individuos, colectivos de arte y negocios pequeños, entre otros, interesados en el tema de la chicha y su ligazón 
cada vez más con lo estético. Desde 2010 hacia adelante tiene una mayor presencia y creación en la ciudad, y se fue consolidando el apelativo de estética chicha, a falta de otra forma de denominar con mayor precisión esta forma de producción.

La gráfica popular que proviene de lo chicha se fue asumiendo en el medio urbano limeño como una forma de expresión artística hasta convertirse en estética chicha. Sin embargo, hay que decir que la masiva creación de ese producto y la manera de catalogarla es reciente: la denominación estética chicha data de inicios de la segunda década de este siglo, se construye como concepto descriptivo, corporizado a partir de las manifestaciones externas del afiche chicha, de su composición, de los colores, no es exactamente una categoría analítica. Aun así, tal designación indica las formas creativas de una sociedad en movimiento. ¿Cómo se produce ese cambio? ¿Cómo se expresa ese movimiento que influyó en el cambio de formato? Esto se produjo en el ámbito de la música chicha. A inicios de este siglo había indicios que algo empezaba a manifestarse, y se daba en el centro mismo del quehacer de la música chicha, de la gráfica chicha, de los afiches chicha. Estos tenían/tienen un contenido, diseño y colores direccionados hacia un sector social específico, con el fin de comunicar las fiestas chicha. El área de la producción gráfica con el tiempo fue adquiriendo vida propia, una independencia relativa, más allá del circuito musical del cual surgió. Este fue el inicio de un giro en la producción del afiche chicha, que dio lugar al afiche chicha de galería, una nueva etapa del afiche chicha, que en su diversificación y expansión fue el germen de lo que hoy se denomina estética chicha. Uno de los baluartes de ese cambio es Elliot Túpac. Estuvieron también, posteriormente, otros jóvenes que provenían de otros barrios de Lima, hijos de migrantes, que vivieron el influjo de la música chicha y tienen una formación de artistas gráficos, plásticos. Están ahí, Ruta Mare, Carga Máxima, Nación Chicha, entre otros. Veamos cómo se produjo el proceso de cambio de Elliot Túpac.

Elliot Túpac salió de las canteras del circuito de producción de la música chicha. Su padre fue/es uno de los productores de afiches chicha. Toda su familia, incluido Elliot Túpac, producían afiches para el productor, músico o grupo musical que luego pegarían en las paredes de los barrios para comunicar a los fans el lugar, la fecha y los grupos de música chicha con los cuales se celebrará la fiesta en la semana. Túpac, a corta edad, sabía todo el proceso de producción de un afiche chicha. Su expectativa con el afiche era otra, era darles un sentido artístico a sus producciones. Por ello, ponía mayor atención a las formas, al diseño, a la composición. Pero sus inquietudes no fueron reconocidas. Elliot recuerda. 
Antes yo me tomaba el tiempo de dibujar, media hora, una hora. Pero ahora hay que hacerlo rapidísimo con la alta demanda. Llegó un momento en que incluso me aburrí de hacer afiches. Me aburrí porque me pagaban lo mismo que le pagaban a uno que hacía letras cuadradas y aburridas, sentí que mi esfuerzo no estaba siendo valorado (La Nación, Chile, 31/10/2010).

Este fue el punto de quiebre, inicialmente emocional, de producir algo más allá de lo funcional. Un trabajo creativo requería más tiempo y el resultado era un producto más elaborado. Los otros se quedaron en el plano publicitario, pragmático funcional. Como decía Panofsky, "cuanto más insista yo en la forma de la escritura, tanto más vendrá a convertirse en una obra de caligrafía” (1987, p. 28). En este caso, Túpac le daba mayor atención a la forma del afiche. E1 resultado vendría a ser otro de mayor elaboración y cuidado en la creación. Sin embargo, para los promotores de espectáculo o algunos grupos musicales solo era un detalle que igual cumplía su función comunicativa. Le generó desazón - “aburrimiento”, dice él一 que no reconocieran el trabajo creativo, que les era indiferente. Sintió que su esfuerzo "no estaba siendo valorado". Ese fue el inicio de un nuevo camino, de un proyecto que empezaba a explorar algo más allá de lo pragmático-funcional. Hasta ahí Elliot Túpac había llegado al tope, a dominar la técnica, el manejo artesanal de producción de afiches, y lo hacía con un estilo que también fue perfilando dentro del trabajo familiar, porque él también era productor de afiches.

Elliot Túpac emerge de las canteras de la música chicha y con el mismo know how de la producción chicha comienza a producir otras propuestas. En menos de una década se producen dos encuentros de distintas coberturas que le posibilitan estar en la escena oficial limeña y, a su vez, en la escena regional latinoamericana. El primero, desde 2003, su primer encuentro, le permite ingresar a la escena oficial de Lima, a través del arte. Sus trabajos van adquiriendo otras dimensiones. Hace carteles, participa en nuevas propuestas, más allá del medio chichero, y en proyectos cinematográficos. El segundo encuentro se produjo en 2010. El gran impulso vino, de nuevo, de un espacio distinto, esta vez, de mayor alcance, más global: de Inglaterra. La prestigiosa revista Creative Review publicó su trabajo y Túpac diseño su portada, y lo colocó en el ámbito internacional. Esto le agenció nuevas relaciones, otras experiencias y esta vez en un ámbito global-regional de América Latina. Fue invitado a Chile, Argentina, etc., para ofrecer talleres, charlas y mostrar su trabajo. En Lima, en 2012 expone en la Galería de Arte Pancho Fierro, su primera exposición individual. Así, su trabajo ingresa a las salas de arte 
formal. En menos de una década pasa de las paredes de los barrios de la ciudad a las salas de arte (Quispe Lázaro, 2016b). Al mismo tiempo, enriquece su producción desde su experiencia foránea e incursiona en otros proyectos y asume otras propuestas, los murales. Su trabajo se diversifica, el estilo chichero toma otros cauces, acentos y otros tonos, pero sin salirse de la característica central en el uso de los colores luminosos, vivos, los fosforescentes, y también los saturados, para darle otras densidades.

En ese trayecto, sus producciones también empiezan a cambiar de alcance y contenido. El trabajo de Elliot Túpac se potencia al asumir una temática de corte social y cultural. Había una referencia, en general, a la identidad, a la colectividad, a la peruanidad, que involucraba al país en su conjunto; Cholo soy, Chola soy, Lima no es el Perú, etc. Ideas de corte cultural, social, identitario en referencia a la colectividad.

Paralelamente, desde 2010 en adelante, en Lima, fueron apareciendo otros actores, creadores, colectivos, y artistas de esta misma propuesta. En 2013 y 2014, la galería del Centro Cultural de España abrió sus puertas a la exposición de arte A mi que chicha en sus dos versiones, I y II. En ellas se dieron a conocer trabajos de nuevos artistitas de origen popular ${ }^{3}$, muchos de los cuales habían desarrollado su actividad por mucho tiempo. Ellos expusieron distintas propuestas temáticas. Lo que inicialmente fue el afiche chicha, hoy se ha diversificado y abarca un conjunto de trabajos que comprende propuestas con distintos formatos, materialidad y estilos. Hoy existen grupos y colectivos (Carga Máxima, Nación Chicha, etc.) ubicados en distintos distritos de la ciudad de Lima con ofertas de producción diversas. A todo ello se le ha denominado estética chicha.

\section{Conclusiones}

La estética chicha se configura como una nueva sensibilidad creativa desde lo popular, impulsada por jóvenes y generaciones anteriores que provienen del ámbito de la música chicha, así como otra legión de jóvenes artistas gráficos, plásticos, hijos de migrantes, que han crecido escuchando este género musical y que asumen esta forma creativa como una forma de reivindicación de lo popular desde la gráfica (Ruta Mare, Carga Máxima, Nación Chicha). Todos ellos crean sus trabajos artísticos asumiendo la característica de lo chicha, y lo ernuevan y dan una cobertura a todos los espacios de Lima. 
La estética chicha tiene un origen que se enmarca en lo popular y desde el circuito de producción de la música chicha, desde el afiche chicha. Adquiere su estilo referente a los colores brillantes y luminosos, llamados fosforescentes, que desde la década de 1980 se impuso en Lima y el país. Fueron identificados como estilo chicha, colores chicha. En el presente siglo, el XXI, como hemos indicado, emerge un nuevo tipo de afiche chicha, y renueva el anterior en diseño, composición y administración de sus elementos. Las figuras 1 y 2 son distintas. Para su diferenciación las hemos nombrado como afiche chicha público, aquel que se visualiza en las calles de Lima, y publicita fiestas chicha; y afiche chicha de galería, aquel que transmite ideas, no publicita fiestas chicha y se expone en ambientes privados, particulares, no públicos, no necesariamente en galerías de arte. Ese ha sido un paso importante que se expresó en la forma, pero supuso un cambio en la lógica de producción, funcionalidad y de expectativas de la nueva generación de jóvenes que provienen del ambiente de la música chicha y su entorno. Además, ellos asumen un nuevo derrotero sin desconocer ni dejar de lado la tradición de la chicha. Este fue el germen de toda una nueva forma de producción que con su diversificación y expansión con otras producciones similares se ha denominado estética chicha.

\section{Notas}

1 Grupos de jóvenes artistas plásticos desde 2003 diseñaron ropa, camisetas y polos con motivos chicha, con dibujos similares a afiches chicha muy coloridos y brillosos (ver http://disenoindependiente-peruano.blogspot.com/search/label/ KMK\%20Dise\%C3\%B1o\%20Chicha).

2 "Partiendo de un examen de los objetos mismos, pueden reconocerse cuatro categorías principales de creaciones populares: 1) objetos artesanales creados en el siglo pasado para las clases medias y acomodadas provincianas; 2) creaciones plásticas empleadas por el campesinado; 3) objetos artísticos de los grupos nativos de la Amazonía, y 4) las artesanías populares manufacturadas para la nueva demanda urbana y turística internacional” (Stastny, 1981, p. 15).

3 Valverde, Monky, Nicolás Torres, Micha, Frank Ventura, colectivo Limafotolibre, Rutamare, Ítalo, Los Salvajes, Juango, Luis Torres Adrían Portugal, Afiches $\mathrm{Hu}-$ pik, Cea Publicidad, Brocha Gorda, Caribeño, José Aguilar, Kalin Rivas, Puse, Lu.cu.ma, Carga Máxima, Arte Cadena, Tumagu, Bendayan, M.D.H., Sierrah, Vipoli. 


\section{Contribuciones del autor}

Arturo Quispe Lázaro ha participado de todo el proceso de elaboración del artículo.

\section{Fuente de financiamiento}

La investigación es autofinanciada.

\section{Conflictos de interés}

Ninguno.

\section{Trayectoria académica}

Arturo Quispe Lázaro es sociólogo de la Pontificia Universidad Católica del Perú, egresado de la maestría de Sociología y diplomado en Estudios de Género en esa casa de estudios. Egresado de la maestría en Historia del Arte en la Universidad Nacional Mayor de San Marcos. Ha realizado diversas investigaciones y publicaciones sobre música y estética popular urbana, estética chicha, migración y cultura popular en el Perú. También ha llevado a cabo investigación sobre género y culturas sexuales en Perú y migrantes mexicanos en la universidad de Columbia, Nueva York (Estados Unidos). Es coautor de El libro de la cumbia, compilado por Juan Diego Parra (Colombia, ITM Institución Universitaria, Discos Fuentes, 2019).

\section{Referencias bibliográficas}

Amigo, R. (2018). Entrevista a José Ruiz Durand. Argentina, Fundación Malba. https:/www.malba.org.ar/evento/artistas-de-la-coleccion-jesus-ruiz-durand/

Bailón, J. y Nicoli, A. (2009) Chicha power. Fondo Editorial de la Universidad de Lima.

Cárdenas, H. R. (2014). Música chicha. La música tropical andina en la ciudad del Cuzco. Ediciones Interculturalidad.org.

Cuyubamba, K. M. (2013). MONKY, el pionero de los afiches chicha. https://issuu. com/monkyartistapopular/docs/portafolio_monky_y_la_publicidad_po

Degregori, C. I. (1984). Huayno, chicha: el nuevo rostro de la música peruana. Cultura popular, (13-14), 187-93. 
Flores-Hora, D. (2006). La reforma agraria o la muerte del latifundio. El pop "achorado" en el Perú. Crítica.cl. Revista Latinoamericana de Ensayo. https:// critica.c1/artes-visuales/la-reforma-agraria-o-la-muerte-del-latifundio-elpop-\%E2\%80\%9Cachorado\%E2\%80\%9D-en-el-peru

Freund, G. (2011). La fotografía como documento social. Editorial Gustavo Gili.

Haciendo Perú TV Perú. (2011). Afiche chicha (parte 1). Haciendo Perú TV Perú. https://www.youtube.com/watch?v=D5fqOi6EnFA

Hurtado, W. (1995). Chicha peruana. Música de los nuevos migrantes. Grupo de Investigaciones Económicas (ECO).

Lauer, M. (2007). Introducción a la pintura peruana del siglo XX. Editorial Universitaria de la Universidad Ricardo Palma.

La Nación. (2010). Carteles chicheros: el flúor de la periferia limeña. La Nación. http://www.lanacion.cl/noticias/site/artic/20101030/ pags/20101030181401.html

Martín-Barbero, J. (mayo-junio de 1999). El miedo a los medios. Política, comunicación y nuevos modos de representación. Nueva Sociedad, (161), 43-56.

Martuccelli. D. (2015). Lima y sus arenas. Poderes sociales y jerarquías culturales. Cauces Editores.

Munive, M. (2003). Lima bidimensional. Identidades, El Peruano (8-9).

Núñez, L. y Llorens, J. A. (1981). De la jarana criolla a la fiesta andina. Quehacer, (9), 107-127.

Panofsky, E. (1987). El significado en las artes visuales. Alianza Editorial.

Portocarrero, G. (2015). Imaginando al Perú. Búsquedas desde lo andino en arte y literatura. Instituto Riva-Agüero.

Quispe Lázaro, A. (2000). Globalización y cultura en contextos nacionales y locales: de la chicha a la tecnocumbia. Debates en Sociologia, (25), 119-142.

Quispe Lázaro, A. (2004). La cultura chicha en el Perú. Construyendo Nuestra Interculturalidad, (1), 1-7. https://www.researchgate.net/publication/221940405_La_cultura_chicha_en_el_Peru

Quispe Lázaro, A. (2013). Del "Perú hirviente" a la "cultura chicha": transculturación y relaciones conflictivas en el medio urbano limeño. En C. Esparza, 
M. Giusti, et al. (eds.), Arguedas: La dinámica de los encuentros culturales. Vol. II (123-135). Fondo Editorial de la Pontificia Universidad Católica del Perú.

Quispe Lázaro, A. (2016a). Chicha music, urban subarlternity, and cultural identities in Peru: Construction of the local and translocal scene. En J. Mendívil y C. Spencer (eds.), Made in Latin America. Studies in popular Music (99110). Routledge.

Quispe Lázaro, A. (noviembre de 2016b). La estética chicha: del barrio a la galería de arte. En MAC-Lima (organizadora). Coloquio internacional hispanoamericano y exposición Juna Acha. Reflexiones contemporáneas latinoamericanas. Museo de Arte Contemporáneo de Lima, Perú.

Quispe Lázaro, A. (2019). Música tropical peruana: la chicha. Construcción de nuevas identidades. En J. D. Parra (comp.). El libro de la cumbia. Resonancias, transferencias y trasplantes de las cumbias latinoamericanas (147-173). Instituto Tecnológico Metropolitano y Edimúsica Discos Fuentes.

Romero, R. (1989). Música urbana en un contexto campesino: tradición y modernidad en Paccha (Junín). Anthropologica, 19-33.

Sánchez, M. (2016). Más allá del pop achorado: una propuesta de relectura de los afiches de Jesús Ruiz Durand para la Reforma Agraria del gobierno de Juan Velasco Alvarado. [Tesis de maestría en Historia del Arte y Curaduría, Pontificia Universidad Católica del Perú].

Stastny, F. (1981). Las artes populares del Perú. Fundación del Banco Continental para el Fomento de la Educación y la Cultura (Edubanco).

Wong, W. (2006). Principios del diseño en color. Gustavo Gili Diseño. 